\title{
Gasification improvement of a poor quality solid recovered fuel (SRF). Effect of using natural minerals and biomass wastes blends
}

\author{
Filomena Pinto ${ }^{\mathrm{a}, *}$, Rui Neto André ${ }^{\mathrm{a}}$, Carlos Carolino ${ }^{\mathrm{a}}$, Miguel Miranda ${ }^{\mathrm{a}}$, Pedro Abelha ${ }^{\mathrm{a}}$, Daniel Direito ${ }^{\mathrm{a}}$, \\ Nikos Perdikaris ${ }^{\text {b }}$, Ioannis Boukis ${ }^{\text {b }}$ \\ ${ }^{a}$ LNEG, Estrada do Paço do Lumiar, 22, 1649-038 Lisboa, Portugal \\ ${ }^{\mathrm{b}}$ HELECTOR S.A., Energy and Environmental Applicat., 25 Ermou Str., 14564 N. Kifissia, Greece
}

\section{H I G H L I G H T S}

- Valorisation of a poor quality solid recovered fuel (SRF) with high ash content and low volatile matter.

- Analysis of the viability production of fuel gas by poor quality SRF gasification.

- Effect of low cost natural minerals on gas quality and yield.

- Decrease of SRF negative bearing by co-gasification of SRF and biomass wastes blends.

- Selection of the most viable applications for gasification.

\section{A R T I C L E I N F O}

\section{Article history:}

Received 31 July 2013

Received in revised form 9 October 2013

Accepted 10 October 2013

Available online 23 October 2013

\section{Keywords:}

Co-gasification

Solid recovered fuel (SRF)

Biomass wastes

$\mathrm{H}_{2} \mathrm{~S}$ and $\mathrm{NH}_{3}$ abatement

\begin{abstract}
A B S T R A C T
The need to produce energy from poor quality carbonaceous materials has increased, in order to reduce European dependency on imported fuels, diversify the use of new and alternative fuels and to guarantee secure energy production routes. The valorisation of a poor quality solid residual fuel (SRF), with high content of ash and volatile matter, through its conversion into fuel gas was studied. The rise of gasification temperature and equivalent ratio (ER) led to higher gas yields and to lower undesirable gaseous components, though higher ER values led to a gas with lower energetic content. To reduce the negative effect of SRF unfavourable characteristics and to diversify the feedstocks used, SRF blended with three different types of biomass wastes: forestry pine, almond shells and olive bagasse was co-gasified. The use of biomass wastes tested was valuable for SRF gasification, as there was an increase in the overall reactivity and in $\mathrm{H}_{2}$ production and a reduction of about $55 \%$ in tar released, without great changes in gas yield and in its HHV. The use of natural minerals mixed with silica sand was also studied with the aim of improving SRF gasification performance and fuel gas quality. The best results were obtained in presence of dolomite, as the lowest tar and $\mathrm{H}_{2} \mathrm{~S}$ contents were obtained, while an increase in gas yield was observed. Co-gasification of this poor quality SRF blended with biomass wastes in presence of dolomite increased gas yield by $25 \%$ while tar contents decreased by $55 \%$.
\end{abstract}

(c) 2013 Elsevier Ltd. All rights reserved.

\section{Introduction}

The total generation of municipal solid waste (MSW) in the EU27 was around 2.52 billion tonnes in 2010 , hence, each EU citizen produced an average of about 5.0 tonnes of waste per year [1]. Therefore, MSW management is a very important issue in modern societies, as even the best planned and managed landfills may bring environmental and public acceptance problems. On the other hand, MSW energetic content is worthwhile to be recovered and used. Landfills generate methane continuously, even after landfill closure, due to anaerobic microbiological activity. As methane is

\footnotetext{
* Corresponding author. Tel.: +35121092 478.

E-mail address: filomena.pinto@Ineg.pt (F. Pinto).
}

a greenhouse gas with commercial value, some effort has been made to use it for energy production. On the other hand, an important number of landfills are not suitable for the implementation of methane recovery systems, which are only viable for large landfills [2]. Thus, the amounts of MSW landfilled have been decreasing about $4.4 \%$ per year in European countries since 2002 [1]. MSW is often treated to be converted into different fractions by size reduction, sieving and separation, which improves its handling properties and homogeneity. Refuse derived fuel (RDF) is obtained by this procedure, it has a higher heating value and has more uniform physical and chemical compositions than MSW.

Therefore, many countries have implemented MSW incineration processes. Some European countries incinerate $38-51 \%$ of the MSW produced [1]. Besides combustion, other thermochemical 